\title{
The Influence of Yarn and Weave Structures on Acoustic Materials and the Effect of Different Acoustic Signal Incidence Angles on Woven Fabric Absorption Possibilities
}

\author{
Bethalihem Teferi Samuel $^{1}{ }^{\mathbb{D}}$, Marcin Barburski ${ }^{1, *}{ }^{\mathbb{D}}$, Jaroslaw R Blaszczak ${ }^{2}$, Ewa Witczak ${ }^{3}$ \\ and Katarzyna Abramczyk ${ }^{1}$ \\ 1 Faculty of Material Technologies and Textile Design, Institute of Architecture of Textiles, Lodz University of \\ Technology, 116 Zeromskiego, St., 90-924 Lodz, Poland; bethalihem.samuel@dokt.p.lodz.pl (B.T.S.); \\ 198304@edu.p.lodz.pl (K.A.) \\ 2 Faculty of Mechanical Engineering, Institute of Turbomachinery, Lodz University of Technology, \\ 219/223 Wolczanska St., 90-924 Lodz, Poland; jaroslaw.blaszczak@p.lodz.pl \\ 3 Lukasiewicz Research Network-Textile Research Institute, 5/15 Brzezińska St, 92-103 Lodz, Poland; \\ ewitczak@iw.lodz.pl \\ * Correspondence: marcin.barburski@p.lodz.pl
}

check for

updates

Citation: Samuel, B.T.; Barburski, M.; Blaszczak, J.R; Witczak, E.;

Abramczyk, K. The Influence of Yarn and Weave Structures on Acoustic Materials and the Effect of Different Acoustic Signal Incidence Angles on Woven Fabric Absorption

Possibilities. Materials 2021, 14, 2814. https://doi.org/10.3390/ma14112814

Academic Editor: Maria Cinefra

Received: 30 April 2021

Accepted: 22 May 2021

Published: 25 May 2021

Publisher's Note: MDPI stays neutral with regard to jurisdictional claims in published maps and institutional affiliations.

Copyright: (C) 2021 by the authors. Licensee MDPI, Basel, Switzerland. This article is an open access article distributed under the terms and conditions of the Creative Commons Attribution (CC BY) license (https:// creativecommons.org/licenses/by/ $4.0 /)$.

\begin{abstract}
Utilizing textile-based acoustic materials can be considered basically from two points of view. First, it may be used as a sound absorbing material. Second, it may be used as a decoration that gives the surrounding area a new artistic appearance. To improve the acoustic possibilities of any woven fabric, it is necessary to study the influences of yarn characteristics and the internal structures of weave interlacement. To understand the impact of the yarn on the fabric, the samples were prepared using only polyester fiber as textured, twisted, and staple yarns. Regarding this experiment, the basic weave's structure type, such as plain, rib, sateen, and twill, were used. Overall, 16 woven fabrics were prepared. The investigation was performed in the range of low to medium acoustic frequencies. The experiments were conducted in an anechoic chamber. Compared to other yarn types, fabrics formed from textured polyester yarn had higher sound absorption properties. Moreover, the observed results show that the different incidence angles of acoustic signals influence the measured sound absorption properties of a textile.
\end{abstract}

Keywords: woven fabric; polyester fiber; sound environment; acoustic barrier

\section{Introduction}

Noise absorption materials are categorized based on resonance absorption, membrane absorption, and porosity absorption. Textile-based materials are classified as porous soundabsorbing materials $[1,2]$.

Porous materials are formed from fibrous materials, composites, and sponges with a small internal diameter of pores, interconnected channels, and cracks or cavities distributed uniformly or randomly throughout the material. The characteristic of the porous structure allows the entrance of sound waves into the material. The friction of sound waves against the pore walls or solid threads enable conversion of the acoustic energy into heat energy which causes the reduction of sound energy. According to the results of other authors, porous materials have good noise absorption properties, particularly in the high-frequency wavebands [3,4].

Woven fabrics are fibrous materials and classified as porous material. Observed by other researchers $[5,6]$, the effectiveness of woven materials for the application of sound absorption is not as effective as nonwoven materials. Specifically, some studies [7,8] show there are problems with low frequency sound absorption for the cases of many porous materials including textiles. However, sometimes unexpected results were observed in specific narrow ranges of these wavebands concerning such materials $[9,10]$. 
The attenuation of the noise by woven material depends on the parameters such as the thickness of the fabric, yarn type and characteristics, interlacement type (weave structure), weaving process parameters, and amount of porous space. The nature of the fiber type influences the sound absorption of any material and the sound absorption is enhanced by a lower yarn linear density and finer yarns, as described in [6,11]. Segura-Alcaraz et al. [5] explain that a jute material has better sound absorption properties than other synthetic materials. Moreover, sound reduction using jute fibers at lower frequencies is more effective in comparison to higher frequencies, besides other yarn characteristics, as mentioned in [12] PES (polyester) textured yarn has the properties of enhanced volume and an improved covering performance for sound absorption material. Regarding the research paper of Soltani and Zerrebini [1], a plain weave structure reduces noise better than other weave types due to the fabric's higher density, shorter free-float, higher interlacement, and higher crimping yarns. To compare to a plain weave, twill fabric has a higher number of thread floats and a lower number of interlacing points. The plain-weave fabrics show stability due to the higher interlacement points of weft and warp yarns.

Additionally, the air permeability performance is much lower than other weave types [10,13-15]. Better sound absorption properties were observed in a sateen weave structure as opposed to double cloth and back weft weaves [6]. This paper also stated that the honeycomb fabric structures have lower sound absorption properties due to their internal open and low-density structures. According to article [16] adding the back air gap increased the honeycomb fabric's sound absorption capacity, particularly at low frequencies.

Additionally, the structure and characteristics of porous fabrics affect the amount of sound that can be absorbed. Woven fabric is formed with two types of porosity: macro and micro-porosity. Micro-porosity is created by a gap between fibers in the yarns, and macro-porosity is formed between the yarn strands. It is primarily determined by the degree of interlacement and the weave type. Regarding porosity, Havlova states [12] that the possibility of predicting the approximate permeability value depends on the linear density of the yarns used and the diameter of the pores (one inter-yarn). The size of the pores of woven fabric also may be deformed and change their shape due to airflow, but this depends on the degree of the interlacing of the yarns. Furthermore, airflow can cause floating yarns, which can result in the formation of new pores on the fabric surface $[17,18]$.

This article aims to examine the effect of yarn and weave characteristics on the sound absorption properties of materials. A total of sixteen woven samples were prepared and used exclusively for this study. Utilizing various yarn characteristics, filament counts, and weave structures for sample preparation enable us to better understand the role of yarn and fabric properties in textile-based acoustic materials. Correlations between weft and warp density, the effect of yarn twist and hairiness, fabric thickness, mass per unit area, and the air permeability of fabrics were analyzed in relation to the results of acoustic tests. Acoustic tests were conducted in an aeroacoustic anechoic chamber $[19,20]$. Taking advantage of the ability to measure the sound absorption capacity of fabrics from various angles, the fabrics were measured at a 45-degree angle. The results of the responses of the woven fabrics to sound transmitted in different angle directions demonstrate the need for more precise applications of textile-based noise reduction materials in the future.

\section{Materials}

During this experiment, 16 woven fabrics were used. Twelve fabrics were woven in the Lukasiewcz Research Network-Textile Research Institute using a Sample Dobby loom SL 8900 S (CCI Tech Inc, Lodz, Poland) with 8 harness frames and 1500 warp yarns for each weave structure. Polyester yarn was used as a raw material in both directions as a warp and weft. Polyester (PES) dtex $167 \times 2(\mathrm{f} 32 \times 2)$ drawn textured yarn (DTY), Polyester (PES) $20 \times 2$ tex staple yarn, and Polyester (PES) dtex $334 \mathrm{f} 32 \times 2$, S95 twisted yarn were used for sample preparation. Four different basic weave patterns (Figure 1), namely, plain, twill, rib, and sateen structures, were prepared from each polyester yarn type (total 12 fabrics). Additionally, four similar basic weave patterns were created using a different weaving 
machine; a Picanol Gamma loom with a Jacquard machine, in the Institute of Architecture of Textiles in the Lodz University of Technology. Samples were created using PES textured yarn dtex $167 \mathrm{f} 32 \times 2$ for the weft and PES textured yarn dtex $167 \mathrm{f} 48 \times 2$ for the warp (Figure 2). Fabric parameters set and yarn types are presented in Table 1.

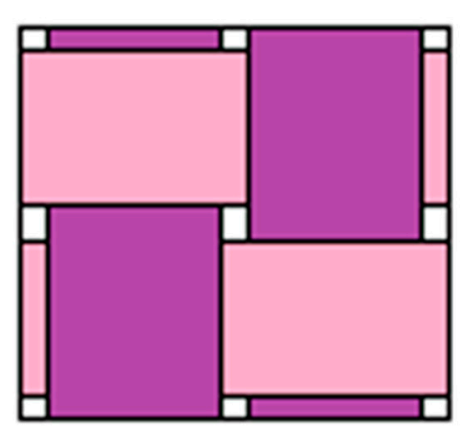

1/1 Plain

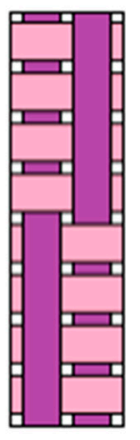

1/1(0001000) Warp Rib

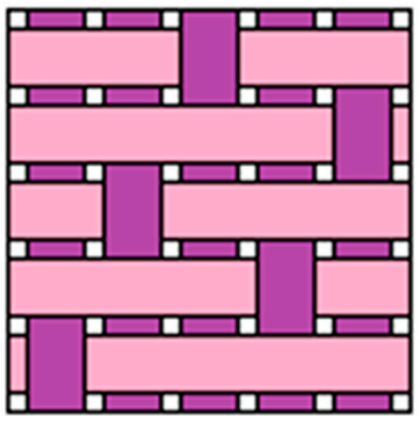

1/4(3) Sateen

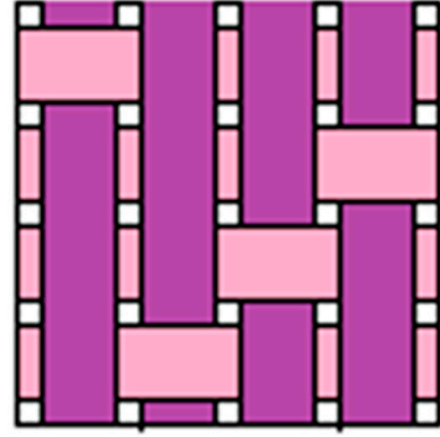

3/1(Z) Twill

Figure 1. Selected fabric structure interlacement.

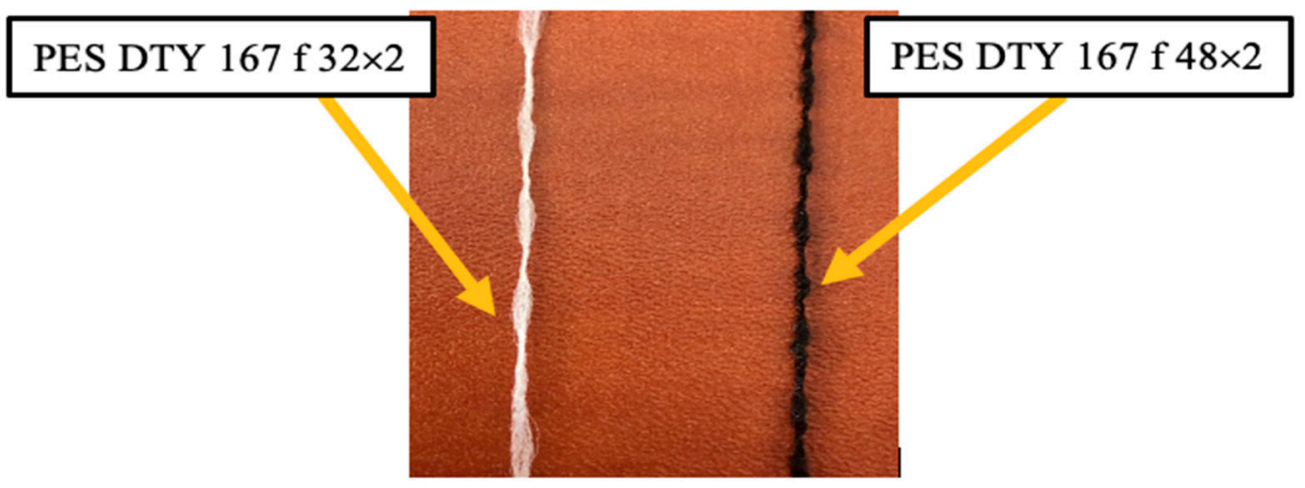

Figure 2. Polyester textured yarn type.

Table 1. Type of yarn and fabric parameters set.

\begin{tabular}{|c|c|c|c|}
\hline Yarn Types & Weave Types & Sample Name & $\begin{array}{c}\text { Set Density } \\
\text { Warp/Weft }(\mathrm{cm})\end{array}$ \\
\hline \multirow{7}{*}{ Textured } & Plain I & $\begin{array}{c}\text { TPI (Textured } \\
\text { yarn-Plain weave I) }\end{array}$ & $30 / 16$ \\
\hline & Rib I & $\begin{array}{c}\text { TRI (Textured } \\
\text { yarn-Rib weave I) }\end{array}$ & $30 / 16$ \\
\hline & Sateen I & $\begin{array}{c}\text { TSI (Textured } \\
\text { yarn-Sateen weave I) }\end{array}$ & $30 / 16$ \\
\hline & Twill I & $\begin{array}{c}\text { TTI (Textured } \\
\text { yarn-Twill weave I) }\end{array}$ & $30 / 16$ \\
\hline & Plain II & $\begin{array}{c}\text { TPII (Textured } \\
\text { yarn-Plain weave II) }\end{array}$ & $30 / 10$ \\
\hline & Rib II & $\begin{array}{c}\text { TRII (Textured } \\
\text { yarn-Rib weave II) }\end{array}$ & $30 / 25$ \\
\hline & Sateen II & $\begin{array}{c}\text { TSII (Textured } \\
\text { yarn-Sateen weave II) }\end{array}$ & $30 / 30$ \\
\hline
\end{tabular}


Table 1. Cont.

\begin{tabular}{|c|c|c|c|}
\hline Yarn Types & Weave Types & Sample Name & $\begin{array}{c}\text { Set Density } \\
\text { Warp/Weft }(\mathrm{cm})\end{array}$ \\
\hline & Twill II & $\begin{array}{c}\text { TTII (Textured } \\
\text { yarn-Twill weave II) }\end{array}$ & $30 / 16$ \\
\hline \multirow{4}{*}{ Staple } & Plain & $\begin{array}{c}\text { SP (Staple } \\
\text { yarn-Plain weave) }\end{array}$ & $32 / 16$ \\
\hline & Rib & $\begin{array}{c}\text { SR (Staple } \\
\text { yarn-Rib weave) }\end{array}$ & $31 / 16$ \\
\hline & Sateen & $\begin{array}{c}\text { SS (Staple } \\
\text { yarn-Sateen weave) }\end{array}$ & $31 / 16$ \\
\hline & Twill & $\begin{array}{c}\text { ST (Staple } \\
\text { yarn-Twill weave) }\end{array}$ & $31 / 16$ \\
\hline \multirow{4}{*}{ Twisted } & Plain & $\begin{array}{c}\text { TwP (Twisted } \\
\text { yarn-Plain weave) }\end{array}$ & $32 / 16$ \\
\hline & Rib & $\begin{array}{c}\text { TwR (Twisted } \\
\text { yarn-Rib weave) }\end{array}$ & $31 / 16$ \\
\hline & Sateen & $\begin{array}{c}\text { TwS (Twisted } \\
\text { yarn-Sateen weave) }\end{array}$ & $32 / 16$ \\
\hline & Twill & $\begin{array}{c}\text { TwT (Twisted } \\
\text { yarn-Twill weave) }\end{array}$ & $31 / 16$ \\
\hline
\end{tabular}

\section{Description of Methodology}

Along with the acoustic absorption efficiency tests, the physical properties of the yarn and woven fabrics were examined, as well as their air permeability. The experiments of the physical properties were conducted to deeply understand the actual behavior and the impact of various yarn characteristics and woven structures on sound barrier material applications.

\subsection{Physical Characteristics of Yarn and Fabrics}

The measurements of the yarn characteristics were performed on polyester-drawn textured yarn, polyester staple yarn, and polyester twisted yarn. The measurements were executed according to standards. The yarn twist was conducted according to ISO 20612010 [21] under normal climatic conditions. According to ISO 2649-1974 [22] (temperature $20{ }^{\circ} \mathrm{C}$, and relative humidity $69 \%$ ), yarn hairiness and yarn evenness were examined using USTER TESTER 3. Table 2 describes each yarn characteristic with different levels of yarn twist, yarn hairiness, and yarn evenness values.

Fabric characteristics that help to predict the performance of the fabrics for the application barriers were examined. The warp and weft densities were determined. Fabric thickness tests were performed with the measurement area of $20 \mathrm{~cm}^{2}$ and at a pressure of $1 \mathrm{kPa}$ according to PN-EN ISO 5084:1999 [23] (temperature $20 \pm 0{ }^{\circ} \mathrm{C}$, and relative humidity $65 \pm 5 \%$ ). Yarn crimp in the fabric was calculated according to ISO 7211-3:1984 [24]. Fabric mass per unit area was tested according to PN-ISO 3801:1993 [25] (temperature $21 \pm 0{ }^{\circ} \mathrm{C}$, and relative humidity $66 \pm 5 \%$ ). Measured construction parameters are presented for the 16 woven fabric samples in Table 3 .

Plain II (TPII), rib II (TRII), sateen II (TSII), and twill II (TTII) are the terms used to describe fabrics created on a Jacquard loom using textured yarn (II). Fabrics were produced on a Sample Dobby loom SL 8900 S (CCI Tech Inc) with textured yarns (I) and are described as plain I (TPI), rib I (TRI), sateen I (TSI), and twill I (TTI). Plain (SP), rib (SR), sateen (SS), and twill (ST) fabrics were fabricated using staple yarn, and plain (TwP), rib (TwR), sateen (TwS), and twill (TwT) structures were prepared using twisted yarn. 
Table 2. Physical properties of three different yarn types.

\begin{tabular}{|c|c|c|c|c|c|c|}
\hline \multirow{2}{*}{\multicolumn{2}{|c|}{ Type of Yarn }} & \multirow{2}{*}{ Yarn twist/m } & \multirow{2}{*}{$\begin{array}{c}\text { Yarn } \\
\text { Hairiness }\end{array}$} & \multicolumn{2}{|c|}{ Yarn Evenness } & \multirow{2}{*}{$\begin{array}{c}\text { Measured Linear Density } \\
\text { of Yarns (Tex) }\end{array}$} \\
\hline & & & & Thin/km & Thick/km & \\
\hline \multicolumn{2}{|c|}{ Textured yarn } & & & & & \\
\hline I & $\begin{array}{l}\text { Warp/Weft } \\
\text { PES DTY dtex } 167 \text { f } 32 \times 2\end{array}$ & & & & & \\
\hline II & $\begin{array}{l}\text { Warp } \\
\text { PES DTY dtex } 167 \text { f } 48 \times 2 \\
\text { Weft } \\
\text { PES DTY dtex } 167 \text { f } 32 \times 2\end{array}$ & & & & & $36.62 \pm 0.04$ \\
\hline \multicolumn{2}{|c|}{$\begin{array}{l}\text { Staple yarn } \\
\text { PES } 20 \times 2 \text { tex }\end{array}$} & 511.4 & 7.24 & 80 & 34.6 & $41.16 \pm 0.09$ \\
\hline \multicolumn{2}{|c|}{$\begin{array}{l}\text { Twisted yarn } \\
\text { PES dtex } 334 \mathrm{f} 64, \text { S95 }\end{array}$} & 90.1 & - & - & - & $36.93 \pm 0.01$ \\
\hline
\end{tabular}

Table 3. Measured construction parameters for 16 woven fabric samples.

\begin{tabular}{|c|c|c|c|c|c|c|}
\hline \multirow{2}{*}{ Samples Name } & \multirow{2}{*}{$\begin{array}{c}\text { Measured } \\
\text { Warp Density } \\
\text { (Ends/cm) }\end{array}$} & \multirow{2}{*}{$\begin{array}{c}\text { Measured Weft } \\
\text { Density } \\
\text { (Picks/cm) }\end{array}$} & \multirow{2}{*}{$\begin{array}{c}\text { Fabric } \\
\text { Thickness } \\
(\mathrm{mm})\end{array}$} & \multicolumn{2}{|c|}{ Crimp \% } & \multirow{2}{*}{$\begin{array}{c}\text { Mass Per Unit } \\
\text { Area, }\left(\mathrm{g} / \mathrm{m}^{2}\right)\end{array}$} \\
\hline & & & & Warp & Weft & \\
\hline TPI & $31 \pm 0$ & $18 \pm 0$ & $0.52 \pm 0.01$ & $8.7 \pm 0.4$ & $0.9 \pm 0.1$ & $195 \pm 1.5$ \\
\hline TRI & $38 \pm 0$ & $17 \pm 0$ & $0.8 \pm 0.02$ & $1.9 \pm 0.1$ & $17.9 \pm 0.7$ & $224 \pm 2.8$ \\
\hline TSI & $34 \pm 0.4$ & $20 \pm 0.6$ & $0.9 \pm 0.03$ & $11.1 \pm 0.1$ & $2 \pm 0.1$ & $213 \pm 2.1$ \\
\hline TTI & $32 \pm 0$ & $18 \pm 0.6$ & $0.79 \pm 0.02$ & $10.9 \pm 0.2$ & $1.8 \pm 0.1$ & $210 \pm 4.2$ \\
\hline TPII & $31 \pm 0$ & $10 \pm 0$ & $0.36 \pm 0.01$ & $6 \pm 0.1$ & $0.9 \pm 0.1$ & $157 \pm 1.8$ \\
\hline TRII & $31 \pm 0.7$ & $27 \pm 0.5$ & $0.5 \pm 0.02$ & $11.4 \pm 0.1$ & $0.8 \pm 0.1$ & $221 \pm 2.4$ \\
\hline TSII & $33 \pm 0$ & $30 \pm 0.6$ & $0.4 \pm 0.03$ & $6.5 \pm 0.2$ & $2.3 \pm 0.1$ & $238 \pm 2.2$ \\
\hline TTII & $31 \pm 0$ & $17 \pm 0.6$ & $0.39 \pm 0.02$ & $7 \pm 0.1$ & $1.2 \pm 0.2$ & $182 \pm 1.9$ \\
\hline $\mathrm{SP}$ & $32 \pm 0.2$ & $17 \pm 0.6$ & $0.57 \pm 0.01$ & $14.7 \pm 0.3$ & $2.3 \pm 0.1$ & $213 \pm 1.6$ \\
\hline SR & $35 \pm 0$ & $17 \pm 0.5$ & $0.74 \pm 0.01$ & $1.3 \pm 0.1$ & $11 \pm 0.2$ & $211 \pm 1.5$ \\
\hline SS & $33 \pm 1.1$ & $16 \pm 0$ & $0.71 \pm 0.03$ & $6.6 \pm 0.1$ & $3.2 \pm 0.1$ & $202 \pm 0.5$ \\
\hline ST & $33 \pm 0.2$ & $18 \pm 0$ & $0.75 \pm 0.01$ & $7.5 \pm 0.3$ & $2.1 \pm 0.1$ & $210 \pm 3.3$ \\
\hline TwP & $31 \pm 0$ & $17 \pm 0.8$ & $0.46 \pm 0.01$ & $7.4 \pm 0.2$ & $0.3 \pm 0.1$ & $189 \pm 0.75$ \\
\hline TwR & $35 \pm 0.1$ & $16 \pm 0.6$ & $0.73 \pm 0.02$ & $3.1 \pm 0.2$ & $11.9 \pm 0.2$ & $203 \pm 2$ \\
\hline TwS & $35 \pm 0$ & $17 \pm 1$ & $0.76 \pm 0.02$ & $5 \pm 0.2$ & $2.5 \pm 0.1$ & $195 \pm 0.63$ \\
\hline TwT & $34 \pm 0.2$ & $20 \pm 1$ & $0.94 \pm 0.01$ & $6.7 \pm 0.2$ & $1.9 \pm 0.1$ & $197 \pm 0.8$ \\
\hline
\end{tabular}

\subsection{Air Permeability Test}

All sixteen samples were subjected to an air permeability test. Regarding each sample, a $20 \mathrm{~cm}^{2}$ surface area on the unwrinkled surface of the fabric was measured, and air pressure drops of $100 \mathrm{~Pa}$ were applied selectively to ten different locations on the sample. All procedures and calculations were completed according to ISO 9237:1995 [26]. Each material's air permeability was determined using the Fx 3300 air permeability tester following a 24-h acclimatization period in normal climatic conditions (temperature $20{ }^{\circ} \mathrm{C}$, relative humidity 65\%). The tests were executed in the Department of Materials Science, Commodity Science and Textile Metrology laboratory at the Lodz University of Technology (Lodz, Poland).

To calculate the air permeability, the following formula was used:

$$
\mathrm{Q}=(\mathrm{qv} / \mathrm{Ap}) \times 167
$$

where

$\mathrm{Q}=$ The velocity of air flow perpendicular to a sample $(\mathrm{mm} / \mathrm{s})$

$\mathrm{qv}=$ The average mean of the air flow $\left(\mathrm{dm}^{3} / \mathrm{min}\right.$ or liter $\left./ \mathrm{min}\right)$ 
Ap $=$ Test area of the specimen $\left(\mathrm{cm}^{2}\right)$

$167=$ Conversion factor from $\left(\mathrm{dm}^{3}\right.$ or liters $/ \mathrm{min}$ and $\mathrm{cm}^{2}$ to $\left.\mathrm{mm} / \mathrm{s}\right)$

\subsection{Acoustic Tests}

Sound absorption tests were conducted in a free-field environment inside the aeroacoustic anechoic chamber in the Laboratory of Aeroacoustics of the Institute of Turbomachinery at the Lodz University of Technology (Figure 3a). Prior to beginning the main tests, the sound levels were measured without any textile for the purpose of validating the measurement system and for reference purposes. Subsequently, the fabrics were tested in the selected frequency ranges according to international standards ISO 26101:2012 [27]. The temperature was $22{ }^{\circ} \mathrm{C}$, and the relative humidity was $65 \%$, and the frequency ranges were $63,125,250,500,1000$, and $2000 \mathrm{~Hz}$.
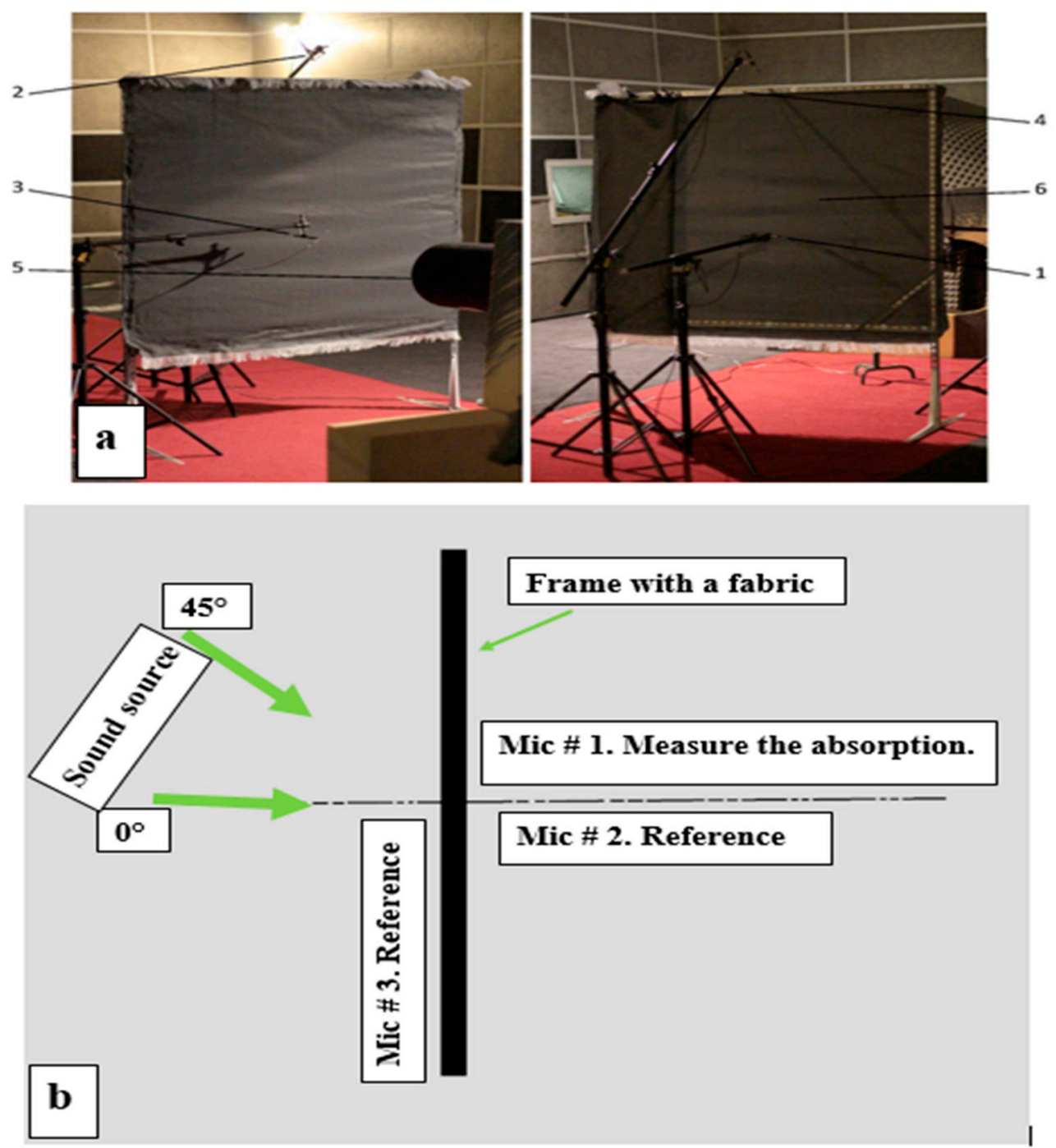

Figure 3. (a) Test stand: 1-microphone \#1, 2-microphone \#2, 3-microphone \#3, 4-frame, 5-the sound source, 6-tested fabric; (b) Top view of the measurement area.

Sound level drops were measured for all samples according to the chosen frequency ranges and at different angle directions. The first test occurred at the center of the fabric by setting the sound source directly in front of the first microphone at the incidence angle of $0^{\circ}$ (Figure $3 \mathrm{~b}$ ). During the second test, the sound source was placed at $45^{\circ}$. Regarding each case, a distance of $1 \mathrm{~m}$ was maintained between the sound source and the fabric surface. The distance between the fabric and microphone \#1 was $0.1 \mathrm{~m}$. Microphone \#2 
was set vertically at the same line above microphone \#1 at $0.1 \mathrm{~m}$ above the frame with the fabric, and was used for checking the reference conditions. Microphone \#3 was placed on a horizontal line to microphone \#1 and the center of the sound source output plane and $0.1 \mathrm{~m}$ apart from the fabric. The fabric on the frame was in the middle of microphones $\# 1$ and \#2. According to the standards, the reference sound pressure level $p_{0}$ was $20 \mu \mathrm{Pa}$. Details of the anechoic chamber experimental procedures and explanations were described in previous papers $[6,8,9,19]$.

\section{Air Permeability Test Results}

\subsection{The Influence of Yarn Type on Air Permeability Results}

Three types of yarns were applied to observe the efficiency of air permeability in woven fabric. The first was the drawn textured yarn (I) shown in Figure 4 (green color). It is characterized as a multifilament yarn, with high bulk due to less twist, soft, and crimp properties. The second was a staple polyester yarn (purple color), described as thin, hairy, and having a higher twist than the other yarns. The third was twisted yarn (dark red color). The number of twists imparted to the thread was between the textured and staple yarns. Thus, the thin and thick places formed throughout the strand give a higher yarn evenness value (Table 2). Low air permeability results were obtained from the overall results with twisted yarn (dark red bar), except for the twill fabric. The second comparable results were obtained with fabrics formed from textured yarn (green bar) in all types of weave structures, and show the second lowest air permeability result. The third result is for staple yarn, which exhibits a high air permeability. (Figure 4).

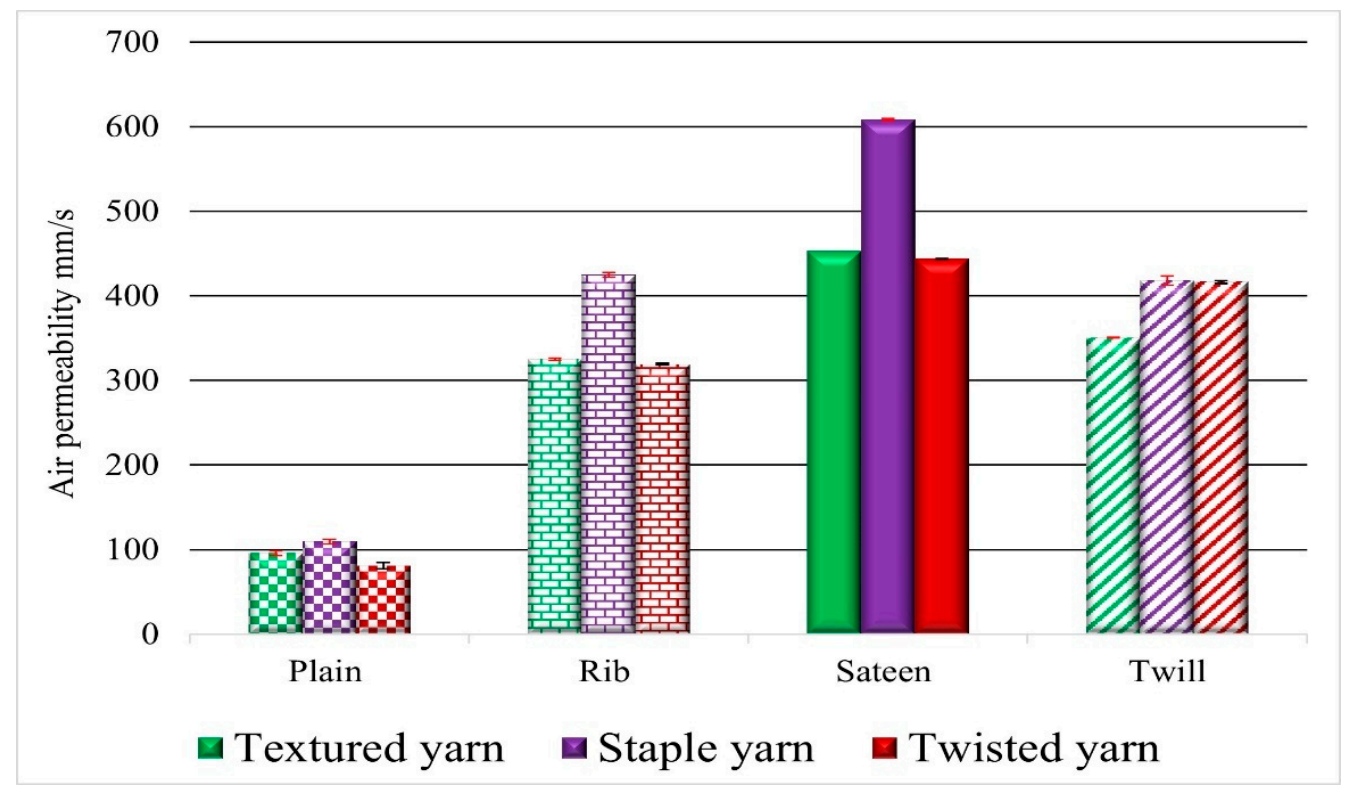

Figure 4. Overall air permeability test results.

\subsection{The Influence of Fabric Structure on Air Permeability Results}

Shown in Figure 4, the patterns in the graph depend on the fabric characteristics, such as a plain fabric structure (rectangular $1 / 1$ pattern) and a twill fabric's distinguishing characteristics (diagonal pattern). The sateen weave on one side is shiny and smooth while, on the other side, it forms a dull effect, and the rib structures are the derivatives of plain fabrics with a floating of yarn in the structure. The structure design was chosen by considering the amount of porous space created by the interlacement and the floating of threads without interlacement. The influence of the inter-geometrical structure of the fabric determines the air permeability directly or indirectly, and the acoustic properties. As the number of interlacements increases, the stiffness of the fabric increases simultaneously and 
prevents the yarn from floating. Yarn floating is a term that refers to a warp or weft yarn that floats over two or more opposing yarns in the fabric structure without interlacing.

The plain fabric structure formed from all PES has a low air permeability result compared to the other fabric structures. Plain fabrics initially have a high interlacement pattern. Accordingly, the interlacement points are higher than the other structures and cause the stiffness behavior of the fabric. This leads to the resistance to air pressure applied by the air. The results for the rib and twill fabric structures are similar. Specifically, rib 1/1 fabrics formed from textured yarn (TRI) and twisted yarn (TwR) have a lower permeability compared to rib (SR) which is formed from staple yarn.

\section{Sound Absorption Test Result}

\subsection{Influence of Yarn Type and Fabric Performance on Sound Absorption}

The sound absorption measurements for all fabrics were performed for 63, 125, 250, 500, 1000, and $2000 \mathrm{~Hz}$ frequency ranges (Figure 5).

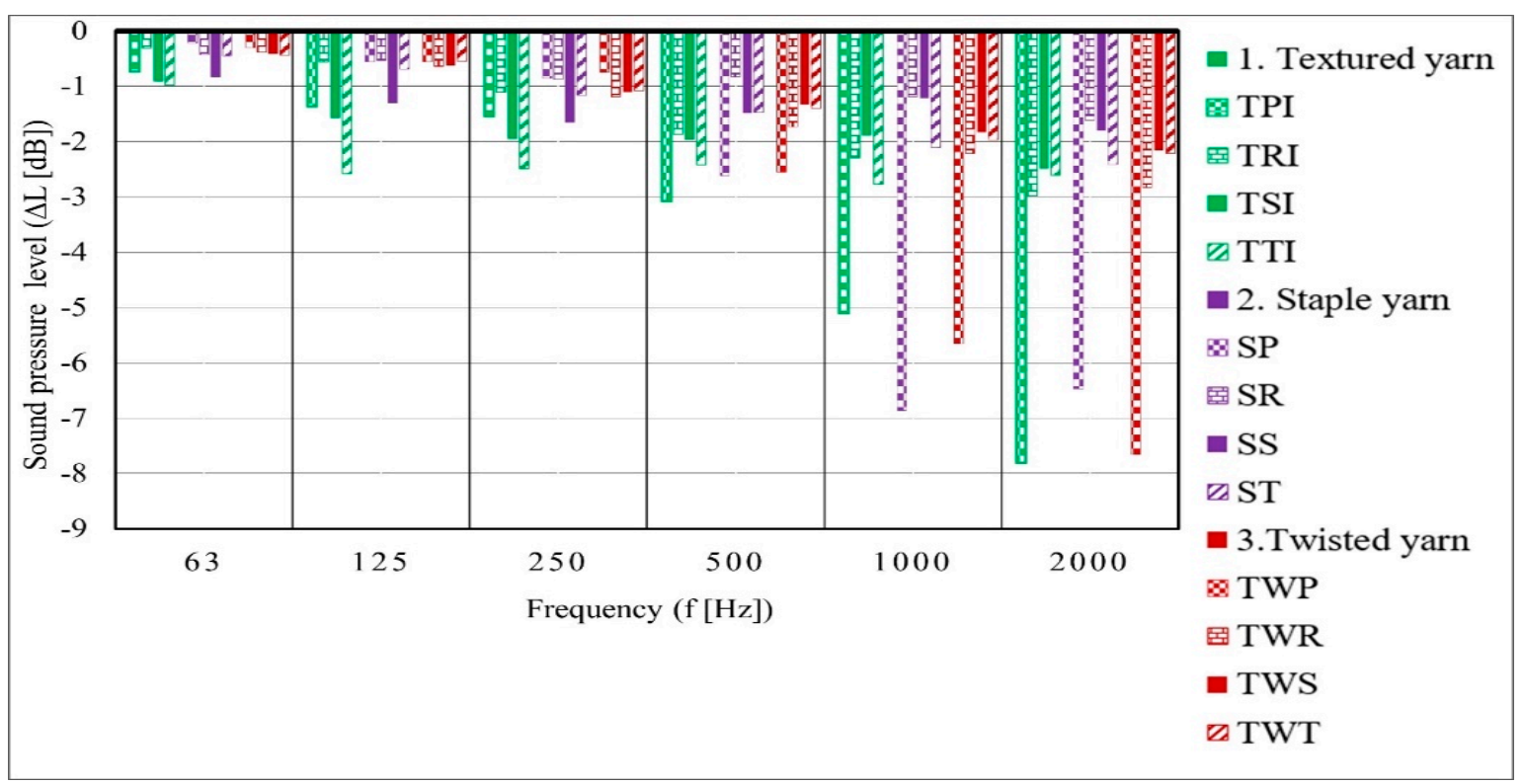

Figure 5. Sound pressure level drop versus frequency range.

The selected woven fabric structure has a low sound absorption performance at lowfrequency ranges (Figure 5). However, the sound absorption performance increases with high-frequency fields. The effectiveness of each fabric type on the sound absorption performance depends on the yarn types. The staple yarn was thin due to a high number of twists per meter compared to other yarn types. While the number of twists imparted increases, the cohesion between fibers also increases. Therefore, the porous space between the fibers becomes smaller, and the yarn becomes thin. The possibility of porous space between the interlacement on the fabric surface increases proportionally as the yarn thickness increases, but this phenomenon may vary depending on the weave structure type. The results indicate that the hairiness of the staple yarns on the fabric has no effect on the sound level drop. Additionally, as an obtained result, the performance of the sound pressure level drop in such fabrics is low. The small number of turns per meter imparted to the twisted PES yarn gives it a higher surface evenness throughout the yarn. The result shows that the sound absorption by fabrics formed from the twisted yarn is higher than the fabrics formed from the staple yarn. The bulkiness of the textured yarn (I) permits the entrance of sound waves between the fiber strands. This phenomenon may increase the chance of the absorption of sound energy between the fibers. To compare, the overall sound level drop indicates that fabrics made of textured yarn (I) have a significantly higher sound absorption than other fabrics. 
The performance of each weave structure in the measured frequency ranges is different. First, at low-frequency ranges of 63-250 (Hz) the TTI weave structure has higher absorption properties compared to other structures. Second, the TSI fabric in the same range shows an intermediate result. Concerning a similar range, the SS structure has the highest absorption and is followed by the ST fabric. The fabrics formed from twisted yarn have the smallest sound level drop at a low frequency between 63 to $250 \mathrm{f}(\mathrm{Hz})$ in comparison to fabrics formed from staple yarn and textured yarn.

Accompanying an increasing frequency $(500 \mathrm{~Hz}$ up to $1000 \mathrm{~Hz}$ ), the TPI, SP, and TwP fabric structures have higher sound pressure level drops. Specifically, SP fabric has a higher sound absorption property at the frequency of $1000 \mathrm{~Hz}$. Other than plain fabric, the twill structures follow with the second highest absorption at $1000 \mathrm{f}(\mathrm{Hz})$ except for the TwT sample. Seen at $2000 \mathrm{f}(\mathrm{Hz})$, the plain weave structure shows higher sound reduction properties than other structures in all yarn types.

The total sound pressure level drop results show (Figure 6) that the textured yarn (I) (green colors) has the highest absorption potential, and it may be concluded that the bulkiness of the yarn increases its ability to absorb sound energy between the fibers. Generally, the fabrics formed from textured yarn (I) in all measured frequencies show a higher sound absorption potential. Conversely, materials created from staple and twisted yarns have comparable outcomes at a low frequency. However, for fabrics with twisted yarn, the absorption potential increases when the frequencies increase. The measurements were performed for every selected frequency range and based on the results the overall acoustic pressure was calculated [20].

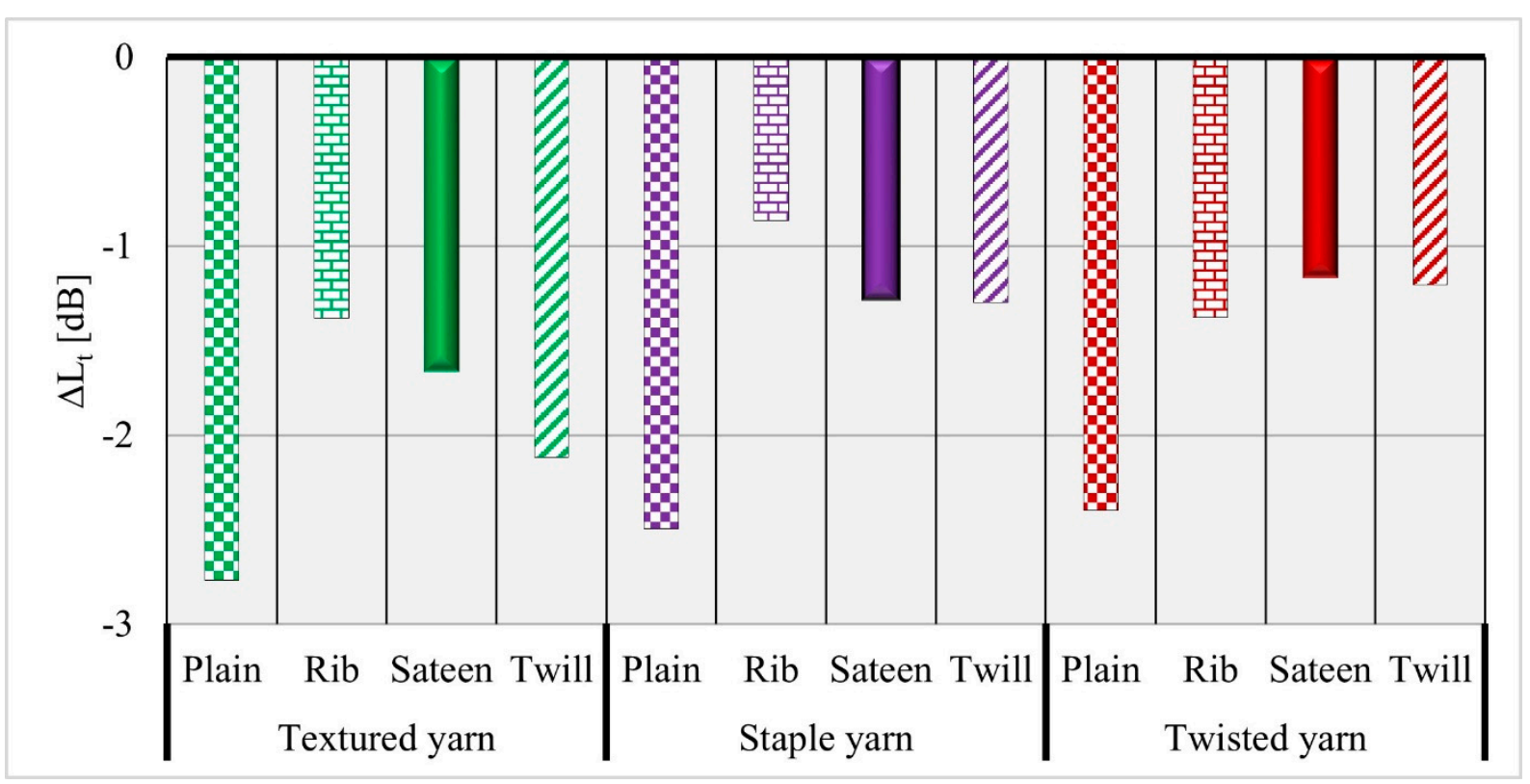

Figure 6. Overall comparison of total sound pressure level drop versus yarn type and fabric structures.

\subsection{The Influence of Yarn and Weave Parameters on the Reduction of Air Permeability and Sound Absorption Potential}

To investigate the effect of yarn characteristics on the sound absorption and air reduction of fabrics, samples were made exclusively from PES textured yarn with varying yarn set densities and filament counts.

The findings indicate that the fabrics produced using textured yarn (I) are completely distinct from those produced using textured yarn (II). The result demonstrates (Figure 7) that TPI has a low air permeability performance compared to TPII. The weft density of the TPI is higher than the TPII. The other fabric structure, TSII, has a low air permeability. The situation could occur because TSII $(33 / 30)$ has a higher density of ends per pick than TSI 
$(34 / 20)$. The increase of the per centimeter yarn count proportionally increases the fabric's density. This raises the possibility of decreasing the fabric's air permeability.

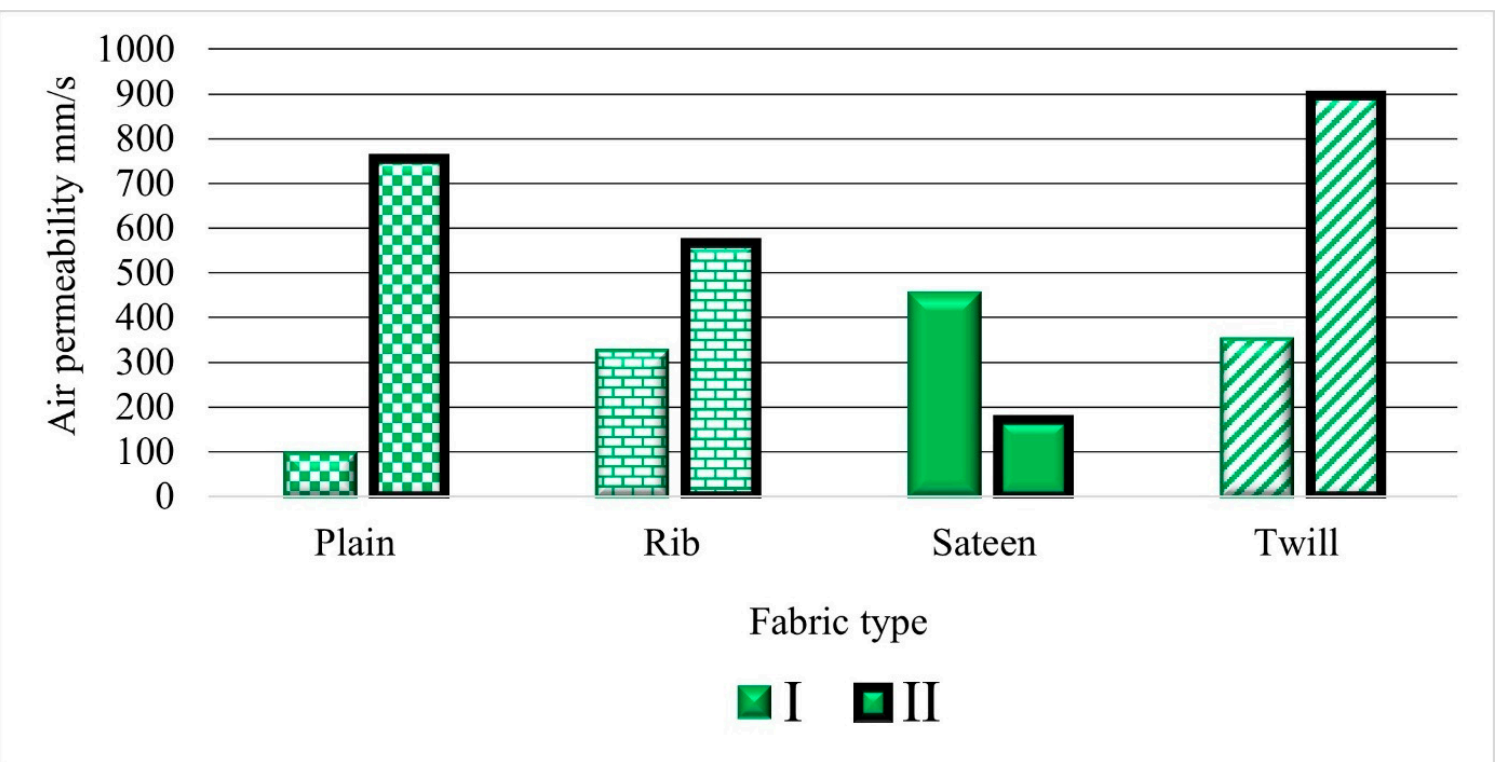

Figure 7. Comparisons based on yarn and weave parameters. Textured yarn (I) and textured yarn (II).

Conversely, TTI and TTII fabrics have a similar density of ends per pick. However, the TTI has higher air reduction properties than the TTII structure. Except for the density, the thickness and crimp percentage of the TTI fabric is higher than the TTII fabric structures. The other reason is that the fabric weave design influences the result of the absorption, such as the sateen weave structure which has a long free float yarn on the surface of the fabric. The fibers in the yarn may move easily from their position while air pressure is applied, and this gives a possibility to let the air flow through the material.

The comparison of the sound absorption of fabric based on yarn parameters shows that the results for the textured yarn (I) fabrics such as TPI, TSI, and TTI fabric structures at low-frequency ranges $(63-125 \mathrm{~Hz})$ show a higher potential than for the textured yarn (II) fabrics (Figure 8).

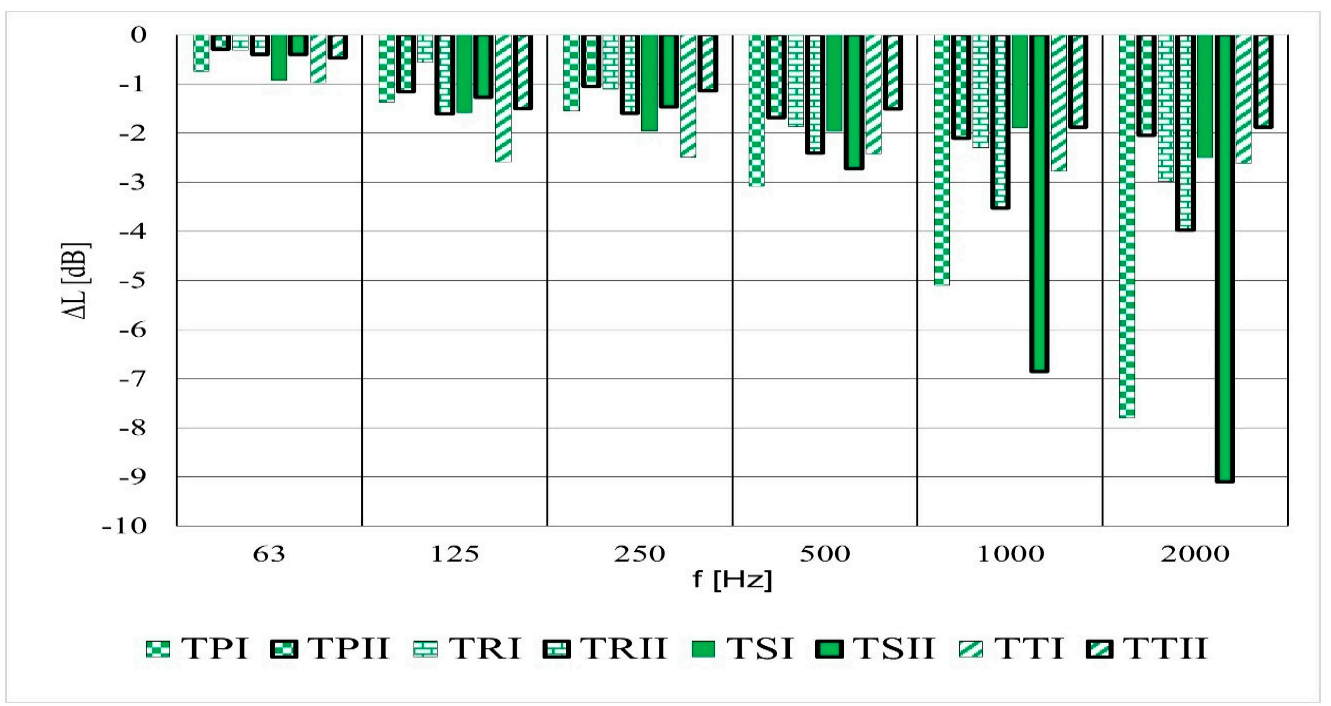

Figure 8. Sound pressure level drop versus frequency; textured yarn (I) and textured yarn (II). 
Conversely, at higher frequency range $(1000 \mathrm{~Hz}$ and $2000 \mathrm{~Hz})$, the TRII and TSII fabrics structures have significantly higher sound absorption properties.

Fabrics formed from textured yarn (I) show that the plain structure has the highest sound absorption potential, aside from the twill fabric (Figure 9). The TSII has the highest sound absorption properties at higher frequency ranges. Additionally, the TRII structure is the second highest sound absorption material.

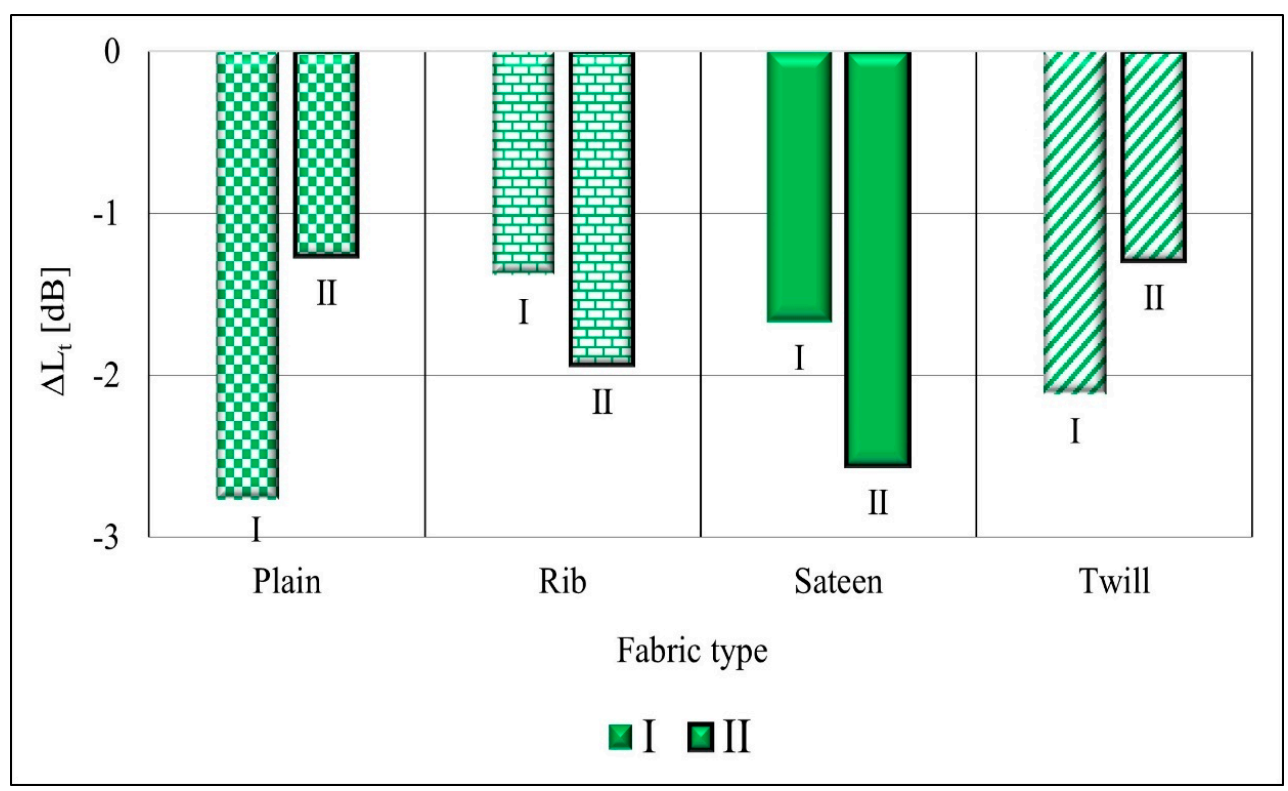

Figure 9. Comparison of total sound pressure level drop between fabrics formed from; textured yarn (I) and textured yarn (II).

Fabrics formed using textured yarn (I) consist of a warp and weft per filament of $5.2 \mathrm{dtex}$, and the fabric formed using textured yarn (II) per filament is $3.48 \mathrm{dtex}$ for the warp and $5.2 \mathrm{dtex}$ for the weft. Consequently, the fabrics which were formed from textured yarn (I) had thicker filaments than textured yarn (II). These phenomena increase the possibility of absorption and it can be concluded that the thickness of the filament in fabrics made from textured yarn (I) increases the possibility of friction of sound energy between the filaments. This may account for the high absorption capacities of fabrics made from textured yarn I.

According to the test results in Figure 10, the plain fabric structure has the highest absorption properties compared to the other structures. The plain fabrics, which are indicated by the green (I), dark red, and purple color with rectangular patterns, have a warp per centimeter between 30 to 34 (Figure 10a) and a weft per centimeter between 16 to 18 (Figure 10b). This indicates a very similar number of ends and picks per centimeter. Shown in Figure 10 ( $a$ and $b$ cases), the results vary depending on the total sound absorption level, from highest to lowest, for the following yarn types: textured yarn (I) (plain I), staple yarn, and twisted yarn. TSII (indicated by a shiny green color) is another structure with a high sound absorption result. It has a similar warp per centimeter as plain fabrics, but it has a higher weft per centimeter than all plain fabric structures. 

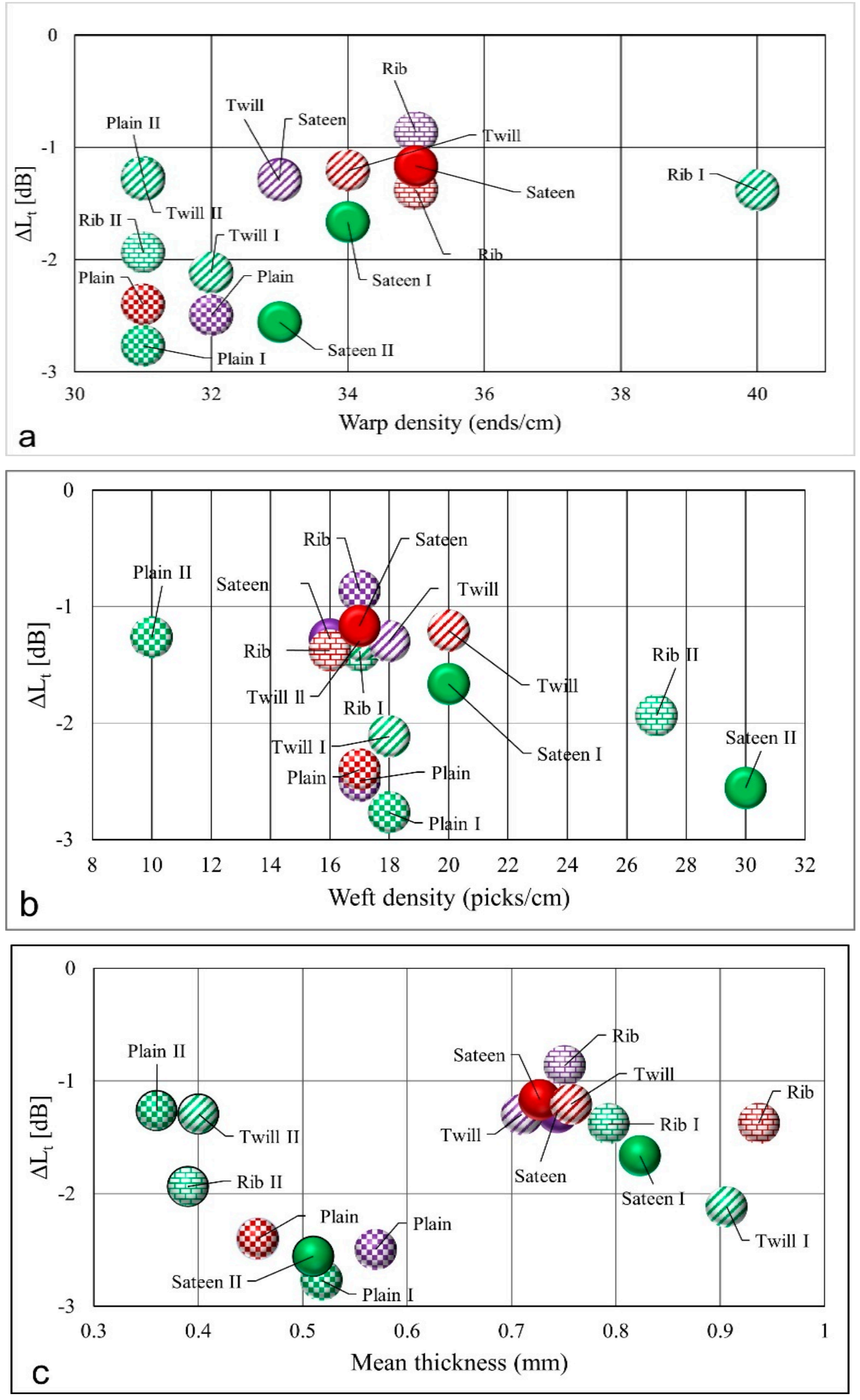

Figure 10. Cont. 

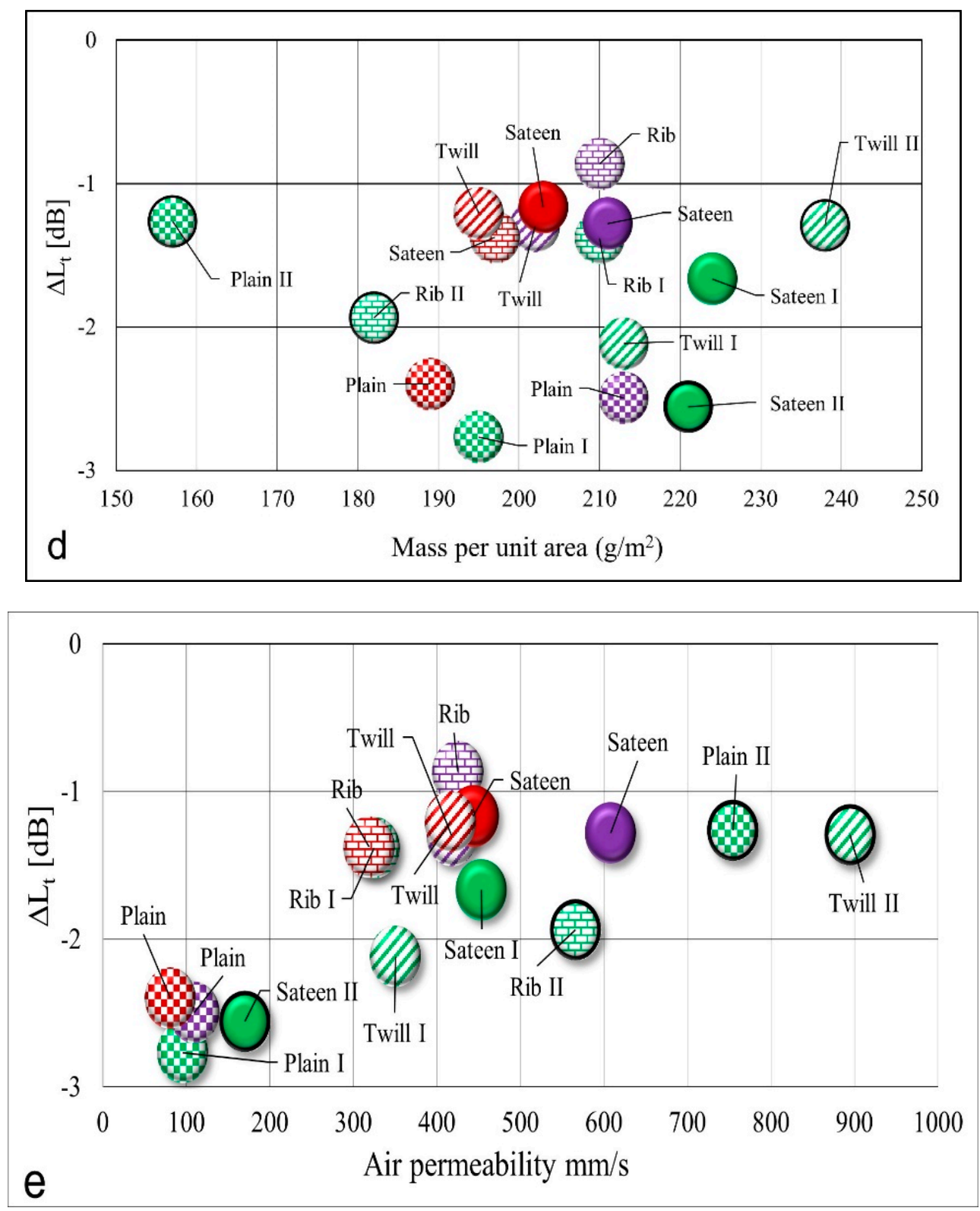

Figure 10. Overall yarn type and fabric properties comparison concerning sound level drop at $0^{\circ}$. (a) Illustrates the relationship between the warp density of fabrics and the total sound pressure level drop. (b) Presents the weft density of fabrics in relation to total sound pressure level drop. (c) Depicts the effect of fabric thickness on fabric total sound pressure level drop. (d) Illustrates the effect of fabric mass per unit area on total sound pressure level drop. (e) Depicts the relationship between the fabrics' total sound pressure level drop and air permeability performances.

Additionally, TSII has a high density compared to the other structures. The thickness properties do not show any significant variations in this research result. The rib (TwR) structure (Figure 10c) has the highest thickness; however, the sound absorption performance is low. The mass per unit area (Figure 10d) of TTII (green diagonal pattern) is higher than the rest of the fabric structures. Nevertheless, the absorption performance of TTII is low.

The relationship between the air permeability and sound reduction properties is inversely proportional. The lower air permeability result foreshadows the higher sound absorption material. Thus, seen in Figure 10e, as the total sound pressure level drops increase, then the air permeability decreases. The comparison between the yarns indicates that the fabrics which are formed from twisted yarn and textured yarn have comparable low air permeability results. However, the sound drop is higher with the fabric formed 
from textured yarn. Generally, the comparison depends on weave structure; a low air permeability and high sound pressure level drop were confirmed on plain weave structures and for the second TSII weave structure.

\subsection{Comparison of the Sound Pressure Level Drop According to Different Angles}

During the tests, it was noticed that the sound absorption property also is influenced by the incidence angle of the sound wave (Figure 11). When the tests took place, the sound source position was changed with respect to the center of the fabric. Hence, the four different fabric structures formed from three yarn types (12 fabrics) revealed different responses according to the sound wave direction. The results for $0^{\circ}$ showed higher sound absorption properties than for $45^{\circ}$. When the angle was changed to $45^{\circ}$, all fabrics showed a slightly lower sound absorption potential.

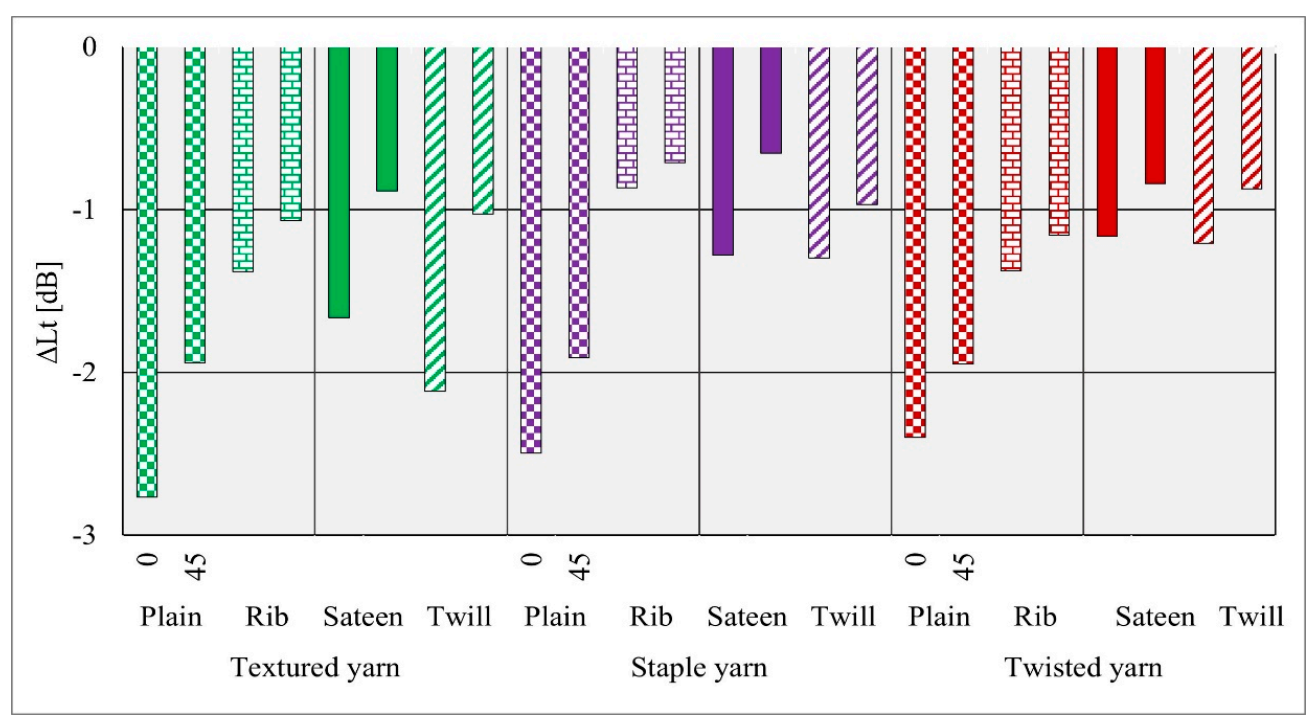

Figure 11. Comparison of sound pressure level drop at the directions of $0^{\circ}$ and $45^{\circ}$.

\section{Summary and Conclusions}

This paper presents the influence of yarn characteristics, weave structure, and the effect of different acoustic signal angles on fabric absorption results.

- Regarding comparison purposes, PES staple yarn was thin and had a high number of twists per meter. The amount of twist imparted on the staple yarn may prevent the entering of sound waves into the yarn strand or it lets sound waves to pass directly without any energy exchange between the strands. The fabrics formed from staple yarn also showed such results in the sound attenuation of the fabrics. Conversely, staple yarn hairiness properties do not significantly affect sound absorption and air permeability potential. Generally, materials formed from the staple yarn show a high air permeability and low sound pressure reduction results.

- Low air permeability results also were recorded for all fabrics formed from twisted yarn, except the twill fabric structure. The textured yarn (PES DTY dtex $167 \mathrm{f} 32 \times 2$ ) has a bulky structure and thick filaments in comparison. The bulkiness enables entrance of the sound waves between the fibers, and the thickness of the filament may increase the chance of sound energy friction with the filaments. This phenomenon may have the potential to dump sound waves between the fibers. High sound absorption results were achieved by all fabrics formed from textured yarn (I).

- The results of measuring in various directions in the anechoic chamber indicate that the acoustic measurements at a $0^{\circ}$ incidence angle showed higher sound pressure level reduction properties in all low and medium frequency ranges than those obtained at 
a $45^{\circ}$ incidence angle. These findings provide guidance for the use of such materials in interior applications such as cinema interior wall coverings and conference rooms. - To obtain the maximum sound absorption potential of the presented materials, the sound source setting position or the incidence angle play decisive roles. Further experiments are in progress, specifically on the relation of the porosity of woven fabrics and the influence of increasing layers on textile acoustic materials.

Author Contributions: Conceptualization, B.T.S., M.B.; methodology, B.T.S., M.B., J.R.B., E.W.; validation, B.T.S., M.B., J.R.B.; investigation, B.T.S., K.A.; resources, M.B., B.T.S., J.R.B., K.A.; data curation, B.T.S.; writing original draft preparation, B.T.S.; writing review and editing, M.B., B.T.S., J.R.B., E.W.; visualization, B.T.S., K.A.; Supervision, M.B., E.W.; All authors have read and agreed to the published version of the manuscript.

Funding: This research received no external funding.

Institutional Review Board Statement: Not applicable.

Informed Consent Statement: Not applicable.

Data Availability Statement: The data presented in this study are available by request to the corresponding author.

Acknowledgments: The project was accomplished by the cooperation of Lukasiewcz Research Network-Textile Research Institute (preparation of samples), Department of Materials Science, Commodity Science, and Textile Metrology at the Lodz University of Technology (air-permeability laboratory) and Laboratory of Aeroacoustics of the Institute of Turbomachinery (Mechanical Department) at the Lodz University of Technology (acoustic experiments). The authors would like to express their gratitude to Iwona Krawczynska and Izabela Jasinska for their technical assistance. The paper was prepared while the first author was a doctoral candidate in the Interdisciplinary Doctoral School at the Lodz University of Technology, Poland.

Conflicts of Interest: The authors declare no conflict of interest.

\section{Nomenclature}

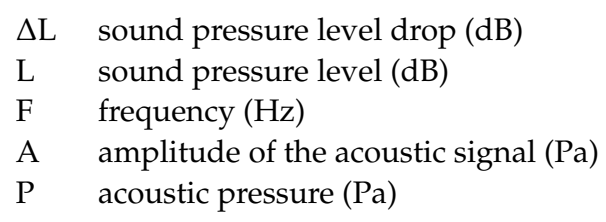

\section{References}

1. Soltani, P.; Zarrebini, M. Acoustic performance of woven fabrics in relation to structural parameters and air permeability. J. Text. Inst. 2013, 104, 1011-1016. [CrossRef]

2. Shrivastava, A. Polymerization. In Introduction to Plastics Engineering; Shrivastava, A., Ed.; William Andrew Publishing: Norwich, NY, USA, 2018; pp. 17-48. ISBN 9780323395007.

3. Cao, L.; Fu, Q.; Si, Y.; Ding, B.; Yu, J. Porous materials for sound absorption. Compos. Commun. 2018, 10, 25-35. [CrossRef]

4. Soltani, P.; Zerrebini, M. Analysis of acoustical characteristics and sound absorption coeff of woven fabrics. J. Text. Inst. 2012, 82, 875-882. [CrossRef]

5. Segura-Alcaraz, P.; Segura-Alcaraz, J.; Montava, I.; Bonet-Aracil, M. The use of fabrics to improve the acoustic absorption: Influence of the Woven Fabric Thread Density over a Nonwoven. Autex Res. J. 2018, 18, 269-279. [CrossRef]

6. Barburski, M.; Blaszczak, J.R.; Pawliczak, Z. Influence of designs of weaves on acoustic attenuation of fabrics. J. Ind. Text. 2019, 49, 33-45. [CrossRef]

7. Qui, H.; Enhui, Y. Effect of Thickness, Density and Cavity Depth on the Sound Absorption Properties of Wool Boards. Autex Res. J. 2018, 18, 203-208. [CrossRef]

8. Blaszczak, J.R. Flow noise correlation with efficiency and vibration level. Syst. J. Transdiscipl. Syst. Sci. 2006, 11, 8-15.

9. Blaszczak, J.R. Acoustic characteristics of an anechoic chamber with an axial two-stage LP model turbine-comparative study. CMP-Turbomachinery 2016, 149, 7-16.

10. Zupin, Z.; Hladnik, A.; Dimitrovski, K. Prediction of one-layer woven fabrics air permeability using porosity parameters. Text. Res. J. 2012, 82, 117-128. [CrossRef] 
11. Witczak, E.; Jasińska, I.; Lao, M.; Krawczyńska, I.; Kamińska, I. The influence of structural parameters of acoustic panels textile fronts on their sound absorption properties. Appl. Acoust. 2021, 178, 1-12. [CrossRef]

12. Havlova, M. Air Permeability and Constructional Parameters of Woven Fabrics. Fibres Text. East. Eur. 2013, 21, 84-89.

13. Paul, R. Functional Finishes for Textiles: An overview. In Functional Finishes for Textiles; Paul., R., Ed.; Woodhead Publishing: Cambridge, UK, 2015; pp. 1-14. ISBN 9780857098399.

14. Shanbeh, M.; Johari, M.S.; Zarrebini, M.; Barburski, M.; Komisarczyk, A.; Urbaniak, M. Effect of weft yarn spinning system on shear characteristics of plain woven fabrics. Text. Res. J. 2020, 90, 10-23. [CrossRef]

15. Kumpikaite, E.; Ragaisiene, A.; Barburski, M. Comparable analysis of end-use properties of woven fabrics with fancy yarns. Part I: Abrasion resistance and air permeability. Fibres Text. East. Eur. 2010, 18, 56-59.

16. Liu, X.; Jiang, J.; Tang, X.; Han, R.; Wang, Q.; Deng, Z. Sound absorption of hollow polyester woven fabric with honeycomb weave. Appl. Acoust. 2021, 180, 108148. [CrossRef]

17. Kuczmarski, M.A.; Johnston, J.C. Acoustic Absorption in Porous Materials. 2011. Available online: https://ntrs.nasa.gov/ citations / 20110011143 (accessed on 16 February 2021).

18. Barburski, M.; Straumit, I.; Zhang, X.; Wevers, M.; Lomov, S.V. Micro-CT analysis of internal structure of sheared textile composite reinforcement. Compos. Part A 2015, 73, 45-54. [CrossRef]

19. Blaszczak, J.R.; Comte-Bellot, G.; Smolny, A. New aeroacoustic facility at the Institute of Turbomachinery, Technical University of Lodz. CMP-Turbomachinery 2005, 128, 79-86.

20. Crocker, M.J. (Ed.) Handbook of Noise and Vibration Control; John Wiley \& Sons: New York, NY, USA, 2007; ISBN 978-0-471-39599-7.

21. ISO. Textile-Determination of Twist in Yarns_-Direct Counting Method; ISO 2061:2010; ISO: Geneva, Switzerland, 2010.

22. ISO. Wool-Determination of Short-Term Irregularity of Linear Density of Slivers, Rovings and Yarns, by Means of an Electronic Evenness Tester; ISO 2649:1974; ISO: Geneva, Switzerland, 1974.

23. PN EN ISO. Textiles-Determination of Thickness of Textiles and TEXTILE Products; PN EN ISO 5084:1999; Polish Committee for Standardization: Warsaw, Poland, 2013.

24. ISO. Textiles—Woven Fabrics—Construction-Methods of Analysis—Part 3: Determination of Crimp of Yarn in Fabric; ISO 7211-3:1984; ISO: Geneva, Switzerland, 1984.

25. PN-ISO. Textiles_Fabrics_Determination of Linear and Area Mass; PN-ISO 3801:1993; Polish Committee for Standardization: Warsaw, Poland, 1993.

26. ISO. Textiles—Determinations of the Permeability of Fabrics to Air; ISO 9237:1995; ISO: Geneva, Switzerland, 1995.

27. ISO. Acoustics_-Test Methods for the Qualification of Free Field Environments; ISO 26101:2012; ISO: Geneva, Switzerland, 2012. 